\title{
NUMERICAL MODELLING AND FULL-SCALE EXERCISE OF OIL-SPILL CONTAINMENT BOOM ON GALICIAN COAST
}

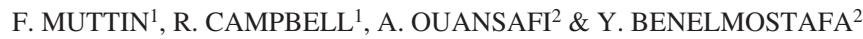 \\ ${ }^{1}$ Engineering School EIGSI La Rochelle, France. \\ ${ }^{2}$ Engineering School EIGSICA Casablanca, Morocco.
}

\begin{abstract}
Using oil-spill booms as floating barriers must respect environmental conditions, mechanical limitations and operational constraints. Numerical modelling of boom behaviour can be used in order to prepare or validate booming plans, which respect these constraints. We present simulations of boom behaviour during an exercise in Galicia to support existing contingency plans. The main inputs of the modelled simulations are: environmental data on meteorology and oceanography, pollution field data and technical specifications of commercially available booms. The barrier structural analysis uses four-step modelling with an adaptive geometry. Modelled results are used in two ways. Firstly, a preparedness approach is conducted with a three-section boom plan to protect a mussel farm near the Puebla del Caramiñal. Secondly, a post-experiment analysis is made with a four-section plan and timedependant boundary conditions given by the five GPS buoys position records carried out during the experiment. This numerical validation of the boom plan is complementary to the operational training of the boom deployment. The model results reproduce the barriers' behaviour during the exercise and improve contingency planning for future response. The proposed approach has been generalized to other environments such as estuaries, ports and lakes.

Keywords: contingency plan, exercise, finite-element, floating barrier, h-refinement, maritime pollution, met-ocean data, modelling, oil-spill.
\end{abstract}

\section{INTRODUCTION}

Oil-spill contingency plans dedicated to mechanical containment of floating oil could benefit from increased synergy between operational training with in-situ exercises and scientific results based on a modelling approach. Maritime activities are often organized to validate procedures and maintain the training levels of operators. Scientific experiments and modelling results can sometimes lack tangible applications to crisis response.

Our objective is to present research work developed during two European projects: ISDAMP+ and ARCOPOL-Platform. We will describe the barrier model approach and demonstrate its application to a real-life experiment deployed in Galicia. The barrier model uses four increasing h-refinements defined respectively as follows: the barrier as segment, catenary, elastic cable, and deformed stretched membrane. The latter two use non-linear finite-element meshes.

Oil-spill modelling (OSM) is a large scientific field, which focusses on many processes: oil spreading, evaporation, emulsification, dispersion, dissolution and sinking. Few oil spill models include the mechanical influence of floating barriers positioned to control drifting oil. The geometric definition of the barrier on the free surface can be a simple line segment, a catenary curve, a strained curvilinear domain or a membrane imbedded at the boundary between the polluted water and the atmosphere. 


\section{MATERIAL AND METHODS}

\subsection{Four-step boom model with adaptive geometry}

The model uses a four-step approach with interconnected geometries in 0D, 1D, 2D and 3D. The first two steps in OD and 1D can be rapidly computed and are fit for adapting already prepared deployment plans to real conditions in case of emergency operational actions. The two more refined steps use the finite-element method to compute the deformation of booms under varying hydrodynamic conditions and can be used to develop and improve response plans.

The four increasing h-refinements of the different steps are defined respectively as follows:

- Barrier segment direction in OD given by eqn (1).

- A catenary curve in $1 \mathrm{D}$ defined by eqn (2).

- A strained cable in 2D stated by eqns (3) and (4).

- A deformed stretched membrane in 3D given by eqns (5) and (6).

The h-refinement increases with the modelling complexity.

The segment direction in $0 \mathrm{D}$ is given by

$$
A=\omega(0,0), B=\omega(0, L), \overrightarrow{A B} \in K_{\vec{V}_{c}},
$$

where $L$ is the boom section length, $A, B$ the boom section end-points, $\overrightarrow{V_{C}}$ the sea current velocity, $\omega$ the boom membrane surface and $K_{\vec{V}_{c}}$ the admissible boom orientation convex.

The catenary curve in $1 \mathrm{D}$ is defined by

$$
\begin{gathered}
s \in[0, L] \rightarrow \xi(s)=(x(s), y(s)), \\
y(s)=\mathrm{a} \cosh \left(\frac{x(s)-b}{a}\right)+c
\end{gathered}
$$

where the curvilinear coordinate $s$ is taken along the boom, $\xi(s)$ is the boom coordinates $x(s)$ and $y(s)$ on the water surface, and a, $b, c$ the catenary coefficients [1]. There is generally a unique coordinate $s$ such that the catenary tangent is normal to the sea current velocity $\frac{d}{d s} \xi(s) \perp \overrightarrow{V_{C}}$.

The strained cable in the 2D step is described by eqns (3) and (4),

$$
\begin{aligned}
s \epsilon[0, L] \rightarrow \xi(s), A & =\xi(0), B=\xi(L), \\
\frac{d}{d s} \vec{T}(\xi(s)) & =p \cdot \overrightarrow{n(s)},
\end{aligned}
$$

where the boom tension vector $T(\xi(s))$ is defined in $\xi(s), p$ represents the hydrodynamic and aerodynamic pressure and $\overrightarrow{n(s)}$ is the normal unit vector at the curve $\xi(s)$.

The set $V$ of admissible membrane displacement field in the 3D step is defined by

$$
V=\left\{u: \omega \rightarrow \mathbb{R}^{3}, u\left(\xi_{1}=0, \xi_{2}\right)=0, u\left(\xi_{1}=L, \xi_{2}\right)=0, u_{Z}\left(\xi_{1}, \xi_{2}=0\right)=0\right\},
$$


where $u$ is the displacement field of the boom surface $\omega, u\left(\xi_{1}=0, \xi_{2}\right)$ is the boom displacement at end-point $A, u\left(\xi_{1}=L, \xi_{2}\right)$ is the boom displacement at end-point $\mathrm{B}, u_{Z}\left(\xi_{1}, \xi_{2}=0\right)$ is the vertical boom displacement near the sea surface and boom floating line, $\xi_{1}$ and $\xi_{2}$ are respectively the longitudinal and transversal curvilinear coordinates of the boom surface. For a curtain-style boom $\xi_{2}=0$ corresponds to the junction between the skirt and the float. The membrane equation in the $3 \mathrm{D}$ step can be written.

$$
\exists u \in V, \forall v \in V, a(u, v)=l(v),
$$

where the virtual displacement field of the boom domain is noted $v$, the elastic strained energy derivative $a$ and the external actions potential energy $l$.

\subsection{Modelling software}

The use of barrier models by operational services dealing with oil-spill contingency plans could improve preparedness. However, software tools must be developed which simplify both modelling and the interpretation of modelled results. We developed a decision support tool, which summarises the different steps of the model in a single window. Figure 1 shows the results of the model, viewable in a geographic information system, on the upper right of the screen. In the results window several key points are summarized: the 2D cable finite-element solution and the sea current vector field (upper left), the numerical value of different thresholds impacting the barrier efficiency (bottom left), and the 3D finite-element mesh of the barrier (bottom right). Results from different times of the simulation can be selected and displayed using the drop-down menu.

\section{EXPERIMENT ON BOOM}

The model was applied in the Ria de Arousa where an exercise took place October, 1st 2014, during the ARCOPOL-Platform project. The objective was to protect mussels farm rafts located near the port of Puebla del Caramiñal. The full-scale experiment using curtain booms was carried out by Galician authorities. The experimentation was conducted in three phases:

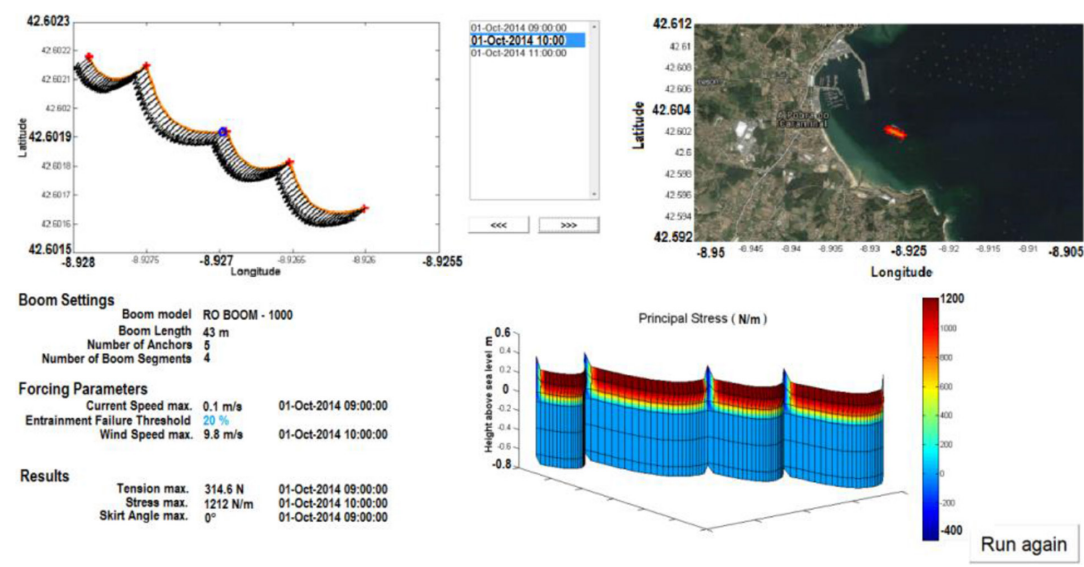

Figure 1: Screen monitoring of four-section boom plan in the Ria de Arousa 10 a.m. October, 1st 2014. BARRIER software developed during the ISDAMP+ project. 
- Setting up a model of the boom deployment on the sea, using geographic, meteorological and hydrodynamic data.

- Installation of an instrumented boom at the entrance of the harbour.

- Validation of the model using measurements and improve the model implementation for future contingency planning.

\subsection{Exercise scenario}

Figure 2 shows the maritime and land spaces surrounding the location of our investigation. Part of this zone was used in a larger demonstration of oil-spill response materials provided by several Galician authorities and stakeholders [2].

Figure 3 shows the contingency plan at the harbour entrance; the yellow star is the location of the harbour.

Red and green marks correspond to mussel rafts. The barrier was deployed near the red curve. The exercise simulated a ship leaking oil (IFO 180 heavy fuel) arriving at the port to search for a refuge berth. An oceanic boom was moored from 10:00 a.m. to 1:15 p.m.

The commercially available floating barrier model used was a 'Ro-Boom 1000', made of Neoprene-Hypalon with a total height (skirt and float) of $0.8 \mathrm{~m}$ and a total length of $200 \mathrm{~m}$. The anchors weighed $45 \mathrm{~kg}$ and used $50 \mathrm{~m}$ mooring chains with tidal compensation.

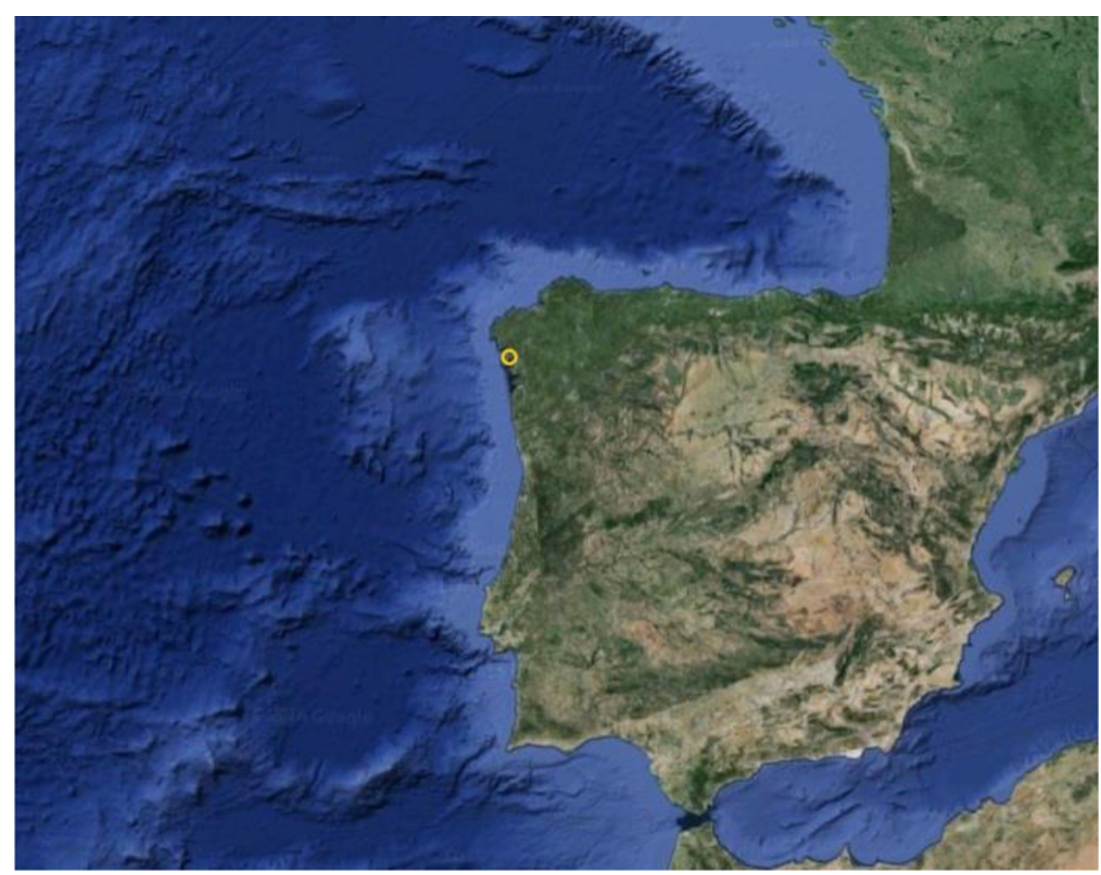

Figure 2: Puebla del Caramiñal Harbour in the Ria de Arousa, Galicia, Atlantic Ocean. 


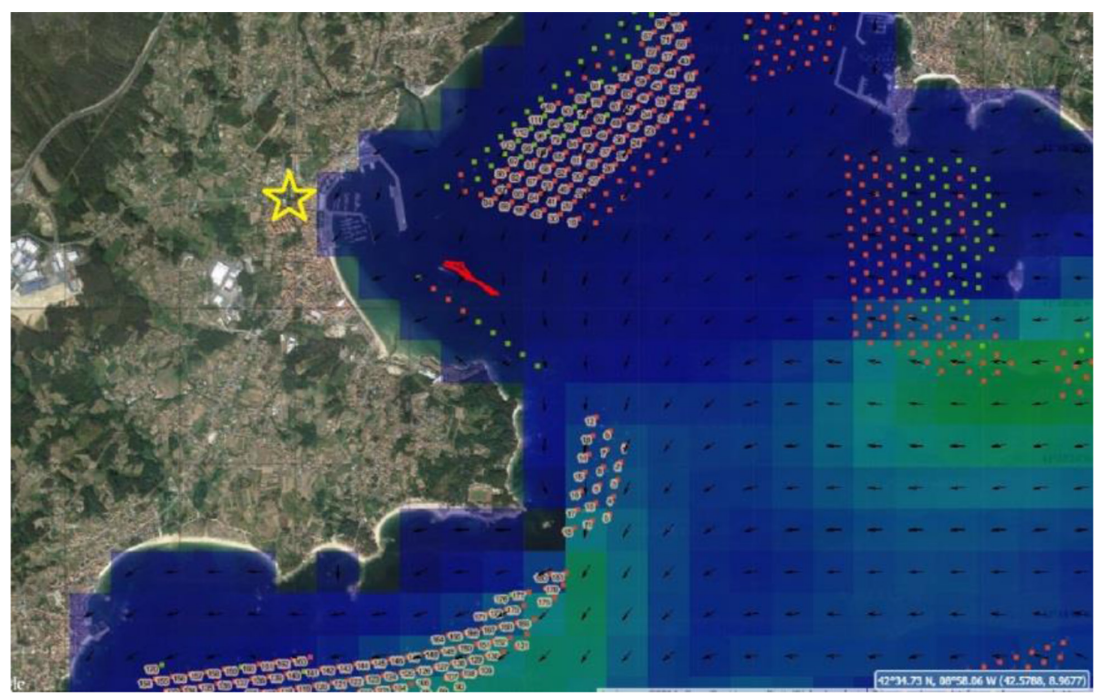

Figure 3: Boom plan at port of Puebla del Caramiñal.

\subsection{Met-ocean data}

The met-ocean data used were the velocities of the atmospheric wind and the oceanographic current. Weather conditions were relatively calm during the exercise, without significant waves in the area; consequently wave action on the barrier was not modelled.

The velocities of the current and wind were available at 10, 11 and 12 a.m. the day of the exercise, 1st October, 2014. Water levels for this day in local time (GMT+2) were high tide $3.10 \mathrm{~m}, 09: 21 \mathrm{a} . \mathrm{m}$. and low tide $1.20 \mathrm{~m}, 3: 35 \mathrm{p} . \mathrm{m}$. The exercise took place after high tide.

Two square finite-difference structured meshes are used with different spatial and temporal resolutions for the water and air flows. For surface currents, the outputs of a regional hydrodynamic model (MOHID) are used at the first sigma layer taken around Finisterre Cape. For winds at the sea surface, the outputs from the lowest layer of a meteorological model (WRF) running at the scale of the North-East Atlantic and the Iberian Peninsula are used. Met-ocean model outputs used for the current and the wind during the experiment are shown in Figure 4.

Met-ocean data characteristics are indicated in Table 1, with spatial and temporal resolutions.

\section{BOOM MODELLING}

These ex-ante model results do not take into account field data and are strictly forecasts.

\subsection{First and second steps in 0D/1D}

The operational point of view generally admits that for current velocity $\overrightarrow{V_{C}}$ module under $0.35 \mathrm{~m} / \mathrm{s}$ the boom orientation convex given by eqn (1) is free $K_{\vec{V}_{c}}=\mathbb{R}^{2}$ and any boom position is acceptable. On the other hand, if the velocity intensity reaches $2 \mathrm{~m} / \mathrm{s}$ the boom orientation must be parallel to the current vector to avoid boom failure. The 'flag position' is the only acceptable boom orientation convex $K_{\overrightarrow{V_{c}}}=\overrightarrow{V_{C}}$ and is a singular catenary. 


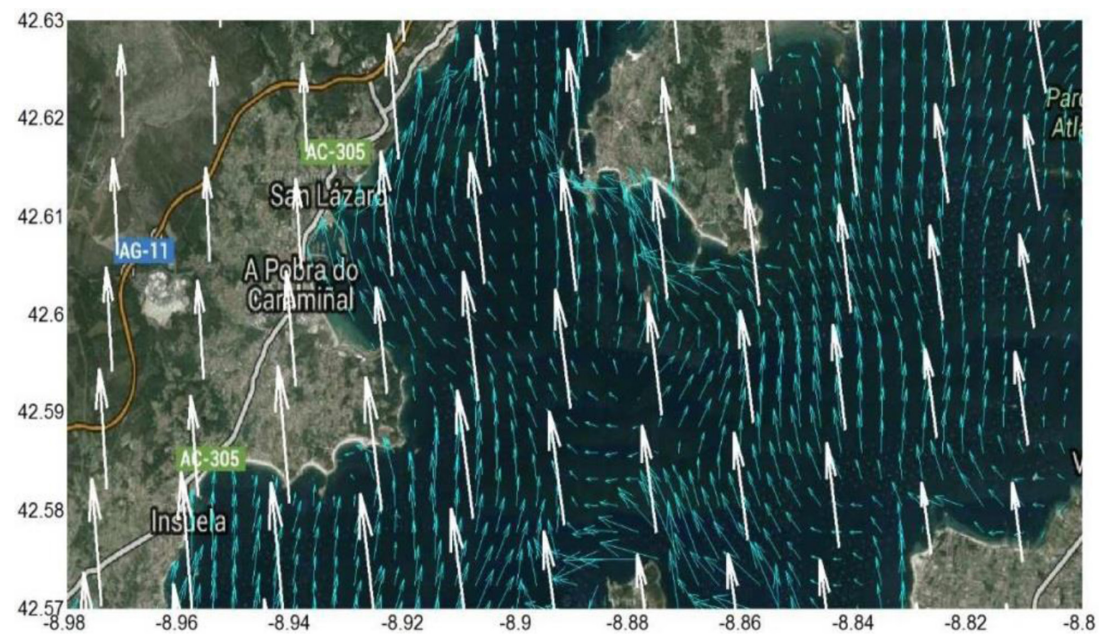

Figure 4: WRF wind (white) and MOHID current (cyan) simulations in the Ria de Arousa, Galicia.

Table 1: Met-ocean model output specifications.

\begin{tabular}{lllll}
\hline Model Type & Model Name & $\begin{array}{l}\text { Horizontal } \\
\text { Resolution (m) }\end{array}$ & $\begin{array}{l}\text { Temporal } \\
\text { Resolution (h) }\end{array}$ & Outputs Used \\
\hline Hydrodynamic & MOHID & 300 & 1 & U,V current \\
Atmospheric & WRF & 1,000 & 3 & U,V wind \\
\hline
\end{tabular}

Considering the above exercise conditions, the maximal current module during the exercise is $0.16 \mathrm{~m} / \mathrm{s}$. Consequently, the boom can be deployed in any orientation. Boom mechanical integrity and hydrodynamic stability are guaranteed.

This suggests that responders may install the boom along any median line $\overrightarrow{A B} \in \mathbb{R}^{2}$ between ship and sensitive area. Reducing oil spread by setting boom as close as possible to the oil emission point is the purpose of oil-spill model and is not developed here.

\subsection{Step three in 2D}

The forecast cable finite-element mesh solution of the barrier behaviour during the exercise is shown in Figure 5. The yellow curve indicates the barrier position at 10 a.m., the white arrows the current direction and the white crosses the boom section ends with mooring chains.

\subsection{Step four in 3D}

Figure 6 shows the deformed 3D finite-element mesh at 10 a.m.

The 3D computation of the finite-element mesh shows pneumatic buckling of the inflated float at each section of the boom plan (Fig. 6). The 3D mesh used for the float does not take into account the manufactured local welding of the tube made to favour free bending. To improve the 3D mesh model this mechanism could be included in future studies. 


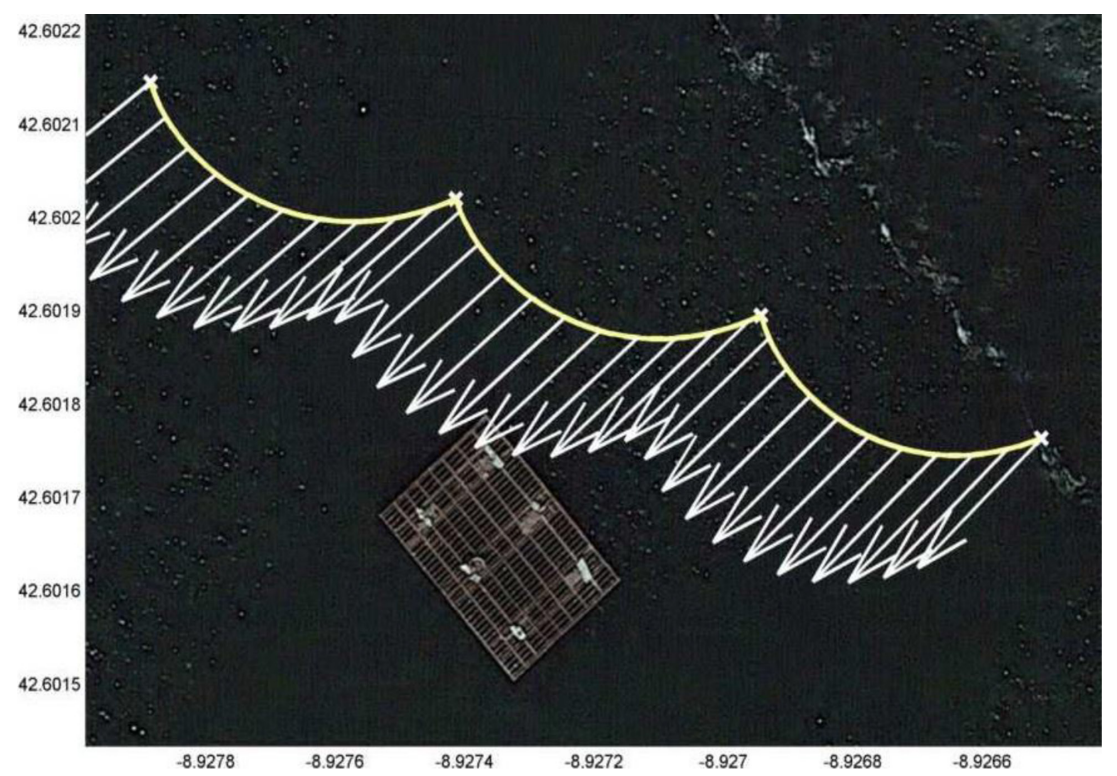

Figure 5: 10 a.m. view of the simulated 2D barrier shape and position with current.

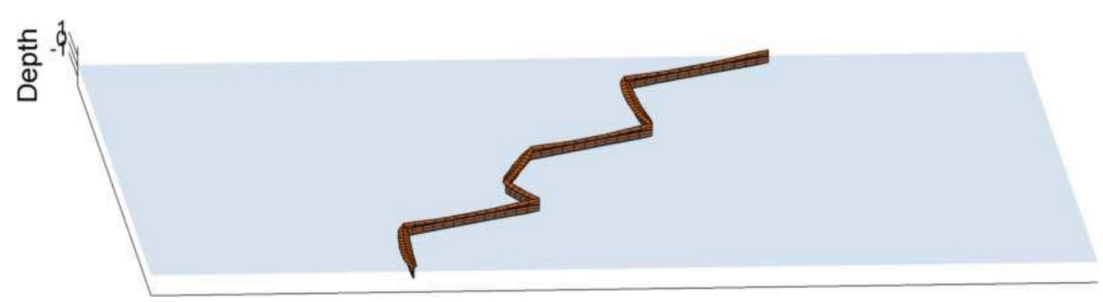

Figure 6: 10 a.m. simulated 3D barrier shape.

Table 2: 3D barrier model results.

\begin{tabular}{ll}
\hline Parameter & Value \\
\hline Current speed $(\mathrm{m} / \mathrm{s})$ & 0.15 \\
Wind speed $(\mathrm{m} / \mathrm{s})$ & 4.39 \\
Maximal tension on anchors $(\mathrm{kg})$ & 18 \\
Maximum skirt vertical angle $\left({ }^{\circ}\right)$ & 3 \\
Entrainment failure risk $(\mathrm{Y} / \mathrm{N})$ & NO \\
\hline
\end{tabular}

The 3D finite-element computation delivers the following results at 10 a.m. shown in Table 2.

The angle of the underwater skirt with respect to the vertical is a mechanical oil containment criteria [3]. At 10 a.m. the maximum skirt angle along the three-section boom plan belongs to the interval $\left[-3^{\circ}, 3^{\circ}\right]$. This value remains well below the threshold of $10^{\circ}$.

The hydrodynamic Lee criteria [4] is computed using the barrier draught and a light oil density of 0.8 . In this case, the entrainment velocity threshold is $0.52 \mathrm{~m} / \mathrm{s}$. At 10 a.m. the threshold velocity is not attained along the boom plan suggesting a correct boom instal- 
lation for the containment of light oil under the studied environmental conditions. An investigation of current intensities over a 24-hour period (Fig. 7) shows that the maximum current velocity $(0.18 \mathrm{~m} / \mathrm{s})$ is well below the threshold velocity for light oil containment. This suggests that the barrier should provide acceptable containment all day for October 1st, 2014.

Anchors tensions are computed by summing the reaction forces at the fixed nodes of the boom section ends. For every hour of October 1st, 2014 the reaction forces at both end-points of one boom section have been computed. The mooring chain tensions are compared with the anchor weight in Figure 8.

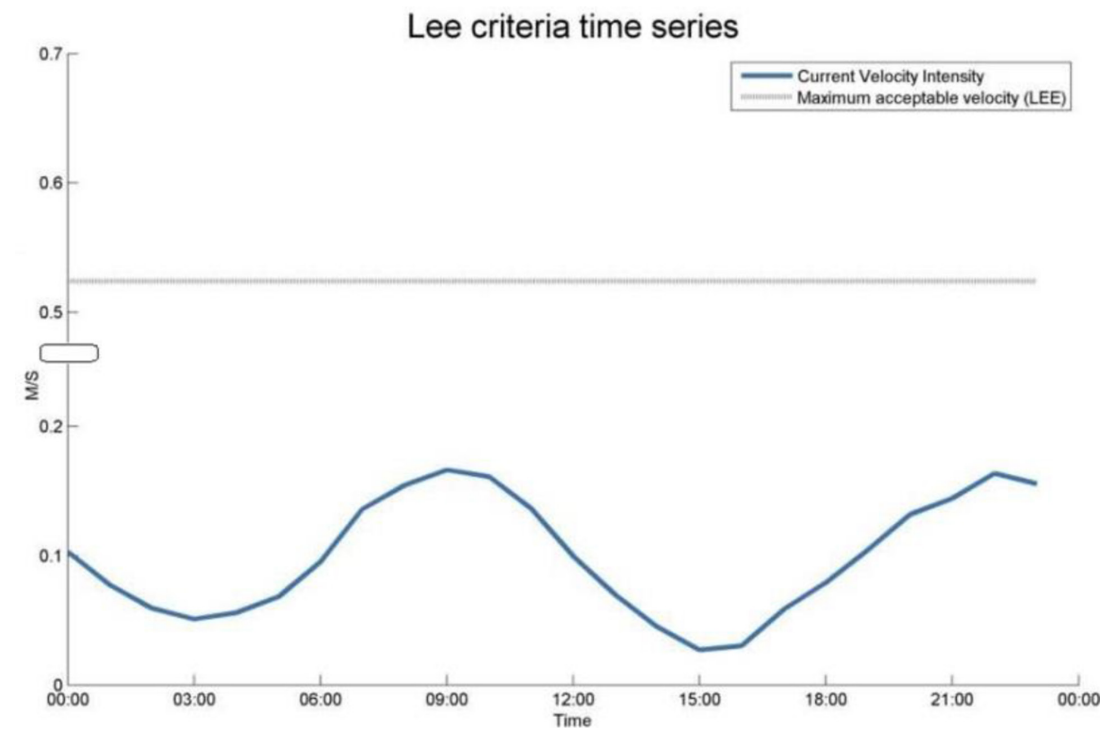

Figure 7: Hydrodynamic oil leakage: Lee's criteria (October 1st, 2014).

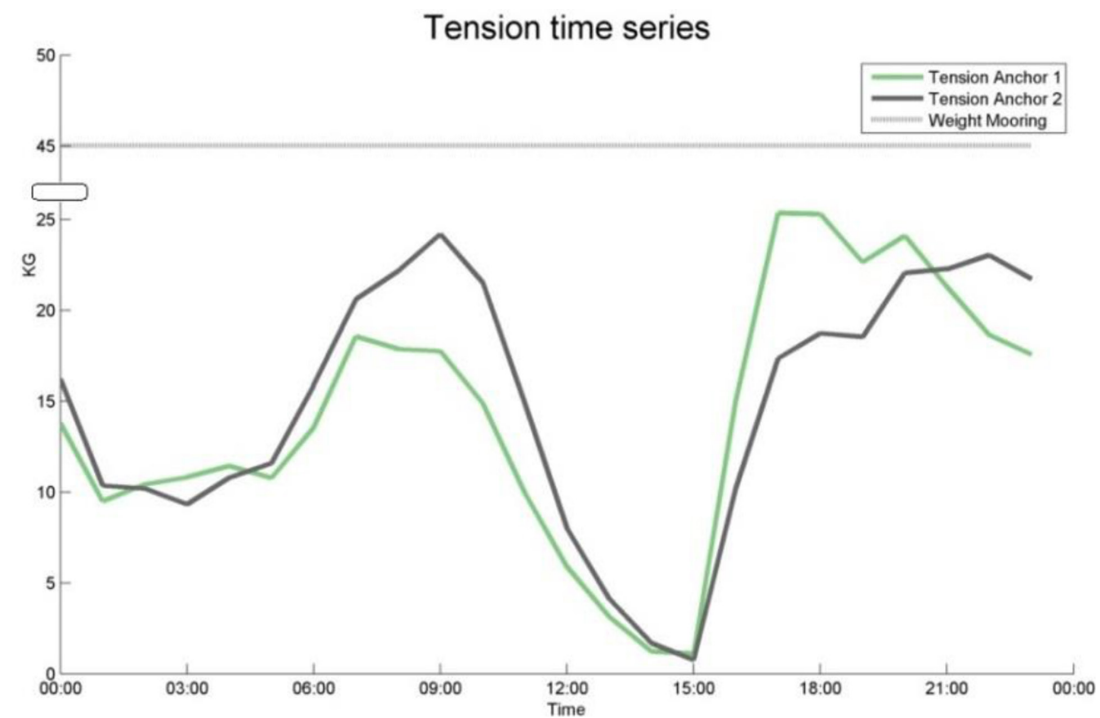

Figure 8: 24-hour time series on anchors tension. 
During boom mooring operations the boom section end-points are anchored one by one. The operators should manipulate different boom anchor's tensions when dismantling.

\section{DEPLOYMENT AND MODEL IMPROVEMENT}

Five drifter buoys (type MD-03) are connected to the barrier. They use a GSM telecommunication to transmit their latitude and longitude coordinates, temperature, active satellites number and battery charge level in real-time. Figure 9 shows one buoy fixed to the barrier during the exercise.

The GPS buoy positions were used as boundary conditions of the boom ends in the post-experiment modelling. By using the five time-dependant buoy positions in the $2 \mathrm{D}$ model we obtain a transient solution of a four-section plan. Figure 10 shows the mesh at each hour of the exercise. Integrating field measurements into the model can be described as re-analysis.

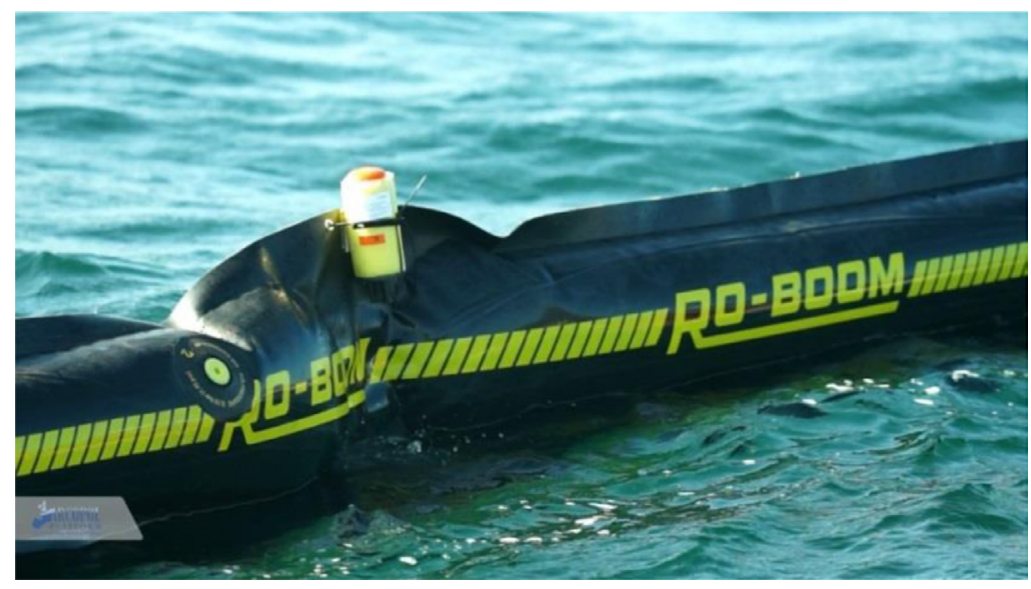

Figure 9: GPS buoy along the floating barrier, photo INTECMAR.

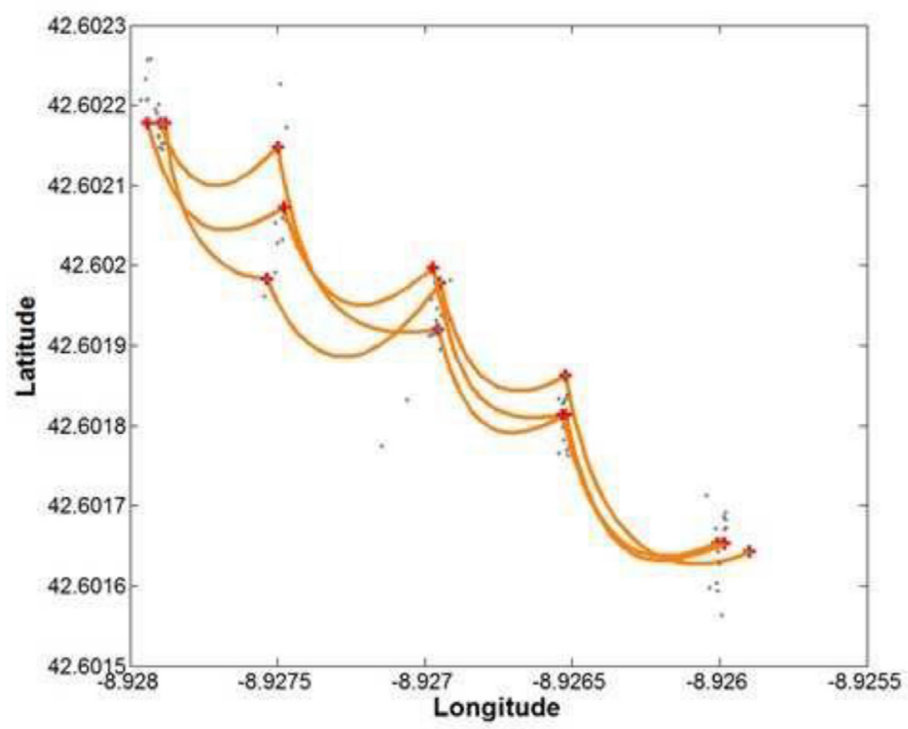

Figure 10: Comparison of the GPS positions along the boom during the exercise (dot points) and the $2 \mathrm{D}$ boom model results (curves). 


\section{DISCUSSION}

The ex-ante model results show the three-section barrier's position in the vicinity of an aquaculture mussel raft without a defined spill position. A spill position can be given by an oil-spill model prediction or by a past measurement. By coupling an oil spill model to the barrier model, a moving boundary for the oil slick drift computation can be defined. Under ideal conditions, the oil is effectively contained by the barrier.

Let us consider the following difference between the forecasting and exercise scenarios. In the forecast barrier model Lee's criteria was computed for light oil while the exercise scenario considered a heavy IFO 180 fuel. Such observed differences suggest the importance of considering different oil types during contingency plan elaboration.

The buoy positions recorded during the exercise are outside the boom section ends, moored to anchors. In the model, these buoy positions are used as Dirichlet boundary condition for boom section ends. For future exercises we suggest installing the GPS buoys along the boom sections to measure the displacement of the boom on the water.

A daily, hour-by-hour representation of the different indicators, along with their threshold values, provides forecasting to responders and contingency planners. This visibility leaves room for flexibility during the intervention, reduces the risk for responders and improves the efficiency of the response plan. Periods when anchor tensions are lower can be identified and used to safely conduct mooring and dismantling, and conversely when anchor tensions are higher risky manipulations can be avoided. These modelled results during a 24-hour period give added value compared to a 3-hour experiment.

\section{CONCLUSION}

This study presents a scientific approach helping better preparedness for spill response in the Ria de Arousa. The mechanical behaviour of a floating barrier anchored on the sea bed is computed using available hydrodynamic and environmental characteristics. A model can help to test and construct efficient contingency plans. The synergy between numerical modelling and oil pollution exercises involves high quality communication between research and operational activities. To that end the quality of the results provided for preparedness action and crisis response depends on the quality of the data used in the model. The exercise described in the Galicia region can be extended to other East Atlantic coastal zones with similar geomorphology and maritime environment.

\section{ACKNOWLEDGMENTS}

The authors acknowledge the support of the ISDAMP+ project funded by the European Commission DG-ECHO 'Humanitarian Aid and Civil Protection' and the Civil Protection Financial Instrument. The authors thank the support of the ARCOPOL-Platform project funded by the European Commission and the Atlantic Area Transnational Programme 'Investing in our Common Future' of the European Regional Development Fund ERDF. The authors thank P. Montero and G. Ayensa for providing the exercise data and measurements.

\section{REFERENCES}

[1] Delgado, L., Kumzerova, E., Martynov, M., Mirny, K. \& Shepelev, P., Dynamic simulation of marine oil spills and response operations. WIT Transactions on The Built Environment, Coastal Engineering VII, WIT Press, 78, pp. 123-133, 2005. 
[2] NETMAR project, Demo at A Pobra do Caramiñal, 1st October 2014, available at: http:// project-netmar.eu/blog/2014/10/demo-at-a-pobra-do-caraminal

[3] Violeau, D., Buvat, C., Abed-Meraïm, K. \& De Nanteuil, E., Numerical modelling of boom and oil spill with SPH. Coastal Engineering, 54(12), pp. 895-913, 2007. http://dx.doi.org/10.1016/j.coastaleng.2007.06.001

[4] Lee, C.M. \& Kang, K.H., Prediction of oil boom performance in currents and waves. Spill Science and Technology Bulletin, 4, pp. 257-266, 1997. http://dx.doi.org/10.1016/S1353-2561(98)00022-X 